\title{
Influence of the Wall Temperature on the Mixture Preparation in DI Gasoline Engines
}

\author{
C. Habchi ${ }^{1}$, H. Foucart ${ }^{1 *}$ and T. Baritaud ${ }^{1}$ \\ 1 Institut français du pétrole, 1 et 4, a venue de Bois-Préau, 92852 Rueil-M almaison Cedex - France \\ e-mail: chawki.habchi@ifp.fr - thierry.baritaud@ifp.fr \\ * Now at Auxirbat
}

\begin{abstract}
Résumé - Influence de la température de paroi sur la préparation du mélange dans les moteurs à essence à injection directe - Des modèles d'interaction spray-paroi et de film liquide ont été développés et appliqués afin de mieux décrire la distribution du carburant dans les moteurs à essence à injection directe sur une géométrie de concept wide spacing. Plusieurs calculs prenant également en compte la combustion ont été effectués pour étudier l'influence de la température du piston sur la préparation du mélange en condition stratifiée. Lors des phases de démarrage à froid, jusqu'à $25 \%$ de la masse injectée participe à la formation d'un film dans le bol du piston. Ceci influe considérablement sur la combustion. L'élévation de la température du piston réduit la quantité de film formé et non brûlé. Il ne reste quasiment pas de film quand sa température dépasse la moyenne entre la température d'ébullition et la température de Leidenfrost du carburant. Ce résultat est en accord avec des observations expérimentales qui confirment l'absence de film liquide pour des températures de paroi supérieures à $460 \mathrm{~K}$.

Mots-clés : Modélisation, moteur, injection directe, préparation du mélange, film liquide, interaction spray-paroi, évaporation.
\end{abstract}

\begin{abstract}
Influence of the Wall température on the Mixture Preparation in DI Gasoline Engines - Spraywall interaction and liquid film models are developed, validated and used to provide better understanding of fuel distribution in a DI gasoline engine with a "wide" concept. Numerical calculations including combustion were performed to study the influence of piston température on mixture preparation under stratified charge operating conditions. During cold operation or cold start, up to $25 \%$ of injected mass forms a liquid film on the piston bowl bottom. This largely affects the combustion efficiency. Increasing piston température decreases the gasoline unburned film amount. No significant liquid film remains on the piston when its température exceeds the mean of the boiling and Leidenfrost temperatures. This result agrees well with the available experimental obervations which confirm the absence of liquid film when piston température exceeds $460 \mathrm{~K}$.

Keywords: Direct injection, mixing, liquid film, spray-wall interaction, evaporation.
\end{abstract}

\section{IN TRO DUCTIO N}

According to recent studies [1-3], the gasoline direct injection (GDI) engine with stratified charge is the most promising way to improve simultaneously fuel ecomomy and performence. For the time being, the GDI engines on the market are based on the wide spacing layout. In this concept, there is a wide distance between the injector and the spark plug. For stratified charge operation, injection is realized near the end of compression stroke. Fuel is transported to the spark plug by air entrainment and by impingement and sliding on the piston top. Therefore, the flow field, the injector features, and the piston shape and temperature are of prime importance. For stratified cold operation, the spray impingement on piston may yield to film formation and large $\mathrm{HC}$ and soot exhaust emissions [4, 5]. Moreover, liquid film may get enough heat from the piston-wall to evaporate, and then decrease the air cooling effect and the compression 
ratio. Thus, studying the wall-spray interaction and liquid film behavior may contribute a better understanding of the mixture preparation including cold starts.

This study explores the wall-spray interaction and liquid film behavior using the KMB code [6] which is a modified version of the Kiva-II code [7]. After a short description of the KMB code, the spray-wall interaction and liquid film models will be presented. As a first validation, we use experimental data provided by a LIF technique [8] to validate the model in configurations reproducing the main characteristics of engine intake pipe flow of port injected SI engines. Next, we use experiments obtained using a light extinction technique to visualize a hollow cone spray impinging on an inclined plate. The last section describes GDI engine calculations taking into account the wall-spray interaction and liquid film models including splashing and evaporation during the mixing process for cold start and warm operating conditions. The influence on combustion is then reported.

\section{THE KMB CODE}

The KMB code [6] is a modified version of the Kiva-II code [7]. The main numerical additional characteristics are its multiblock structured mesh and more accurate Lagrangian and Eulerian solvers. The latest version 7.0 is rewritten in Fortan 90 and may be used on several computer architectures (Nec SX4, Cray/Silicon Origin 2000, etc.). Several submodels were added to the code allowing computations of high pressure DI Diesel engines (fuel drop collision, atomisation and breakup [9], evaporation, combustion, $\mathrm{NO}_{\mathrm{x}}$ and soot [10]), as well as of SI engines (homogeneous [11], stratified charge combustion [12-14]).

\section{MO DEL DESCRIPTION}

Few 3D codes allow wall-spray interaction and liquid film transport including evaporation and boiling on hot internal engine surfaces. O'Rourke et al. [15] included a liquid film model in the code Kiva-3V [16] using the particle Lagrangian approach of the Kiva spray description. Nagaoka et al. [17] used a particle film model in 3D calculations of SI engines. Stanton et al. [18, 19], Bai et al. [20] and AhmadiBefrui et al. [21], Foucart et al. [22, 23], have developed liquid film models using eulerian continuous approaches. The major physical mechanisms affecting the liquid film are (Fig. 1):

- the film formation by impinging droplets and vapor condensation;

- the film spreading due to air and wall shear stress and body forces;

- the heat exchange with walls and the surrounding gas;

- the evaporation, boiling and splashing.

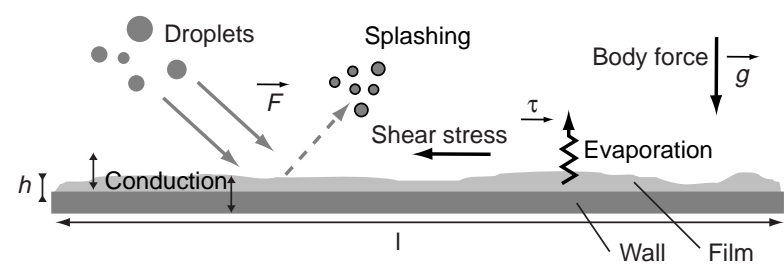

Figure 1

The physical mechanisms affecting the liquid film.

In this work, the basic assumptions are made for film modeling. Then, the governing equations are derived and numerical schemes incorporated into the KMB code.

\section{INTEG RAL FILM EQ UATIO NS}

To build liquid film equations, the following assumptions have been made:

- The liquid film is assumed to be thin enough so that the incompressible boundary layer approximations can be applied. This thin film assumption is justified by estimations done in [8] and [20] which reveals that the maximum film thickness is less than $500 \mu \mathrm{m}$ for typical SI engine conditions.

- The liquid film flow is laminar, though it may have waves on its surface. The liquid Reynolds number is assumed to be less than 500 .

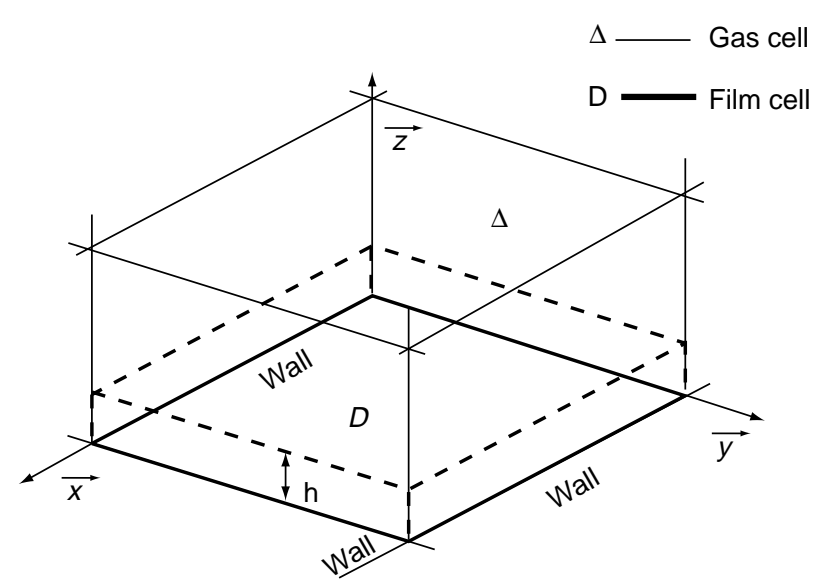

Figure 2

Wall liquid film control volume.

The boundary layer approximations of the conservation equations for mass, momentum and energy have been integrated across the film thickness in each Kiva-II wall-cell. Using the control volume $D$ and the notation shown in Figure 2, the equations are reduced to the following integral two dimensional form where $h$ is the film thickness, $\rho$ is the 
density, $v$ is the cinematic viscosity, $k$ is the thermal conductivity, $c_{p}$ is the specific heat, $p$ is the pressure, $\vec{g}$ is the body force, $T$ is the temperature, $\vec{U}$ is the integral liquid film velocity, $\overrightarrow{V_{w}}$ is the velocity of the wall and $\vec{n}$ is the unit outward normal vector.

Since the liquid is incompressible, integral continuity, momentum and enthalpy equations are written using the liquid volume $V_{D}$ rather than the mass. The film thickness is calculated using:

$$
h=\frac{V_{D}}{A_{w}}
$$

where $A_{w}$ is the wall-cell face area which may change due to the wall motion or mesh relaxation.

\section{CON TIN UITY}

$$
\underbrace{\frac{\mathrm{d} V_{D}}{\mathrm{~d} t}}_{\{1\}} \underbrace{\oint_{\partial D} h\left(\vec{U}-\overrightarrow{V_{w}}\right) \cdot \vec{n} \mathrm{~d} l l}_{\{2\}}=\dot{S}
$$

$\{1\}$

$\{2\}$

In this equation, $\{1\}$ is the Lagrangian time derivative of the liquid volume $V_{D},\{2\}$ is the convective volume term which expresses the flow rate across the boundary lines $\partial D$. The source term $\dot{S}$ represents the rate of fuel at the liquid-gas interface due to the droplets impingement, splashing, evaporation or condensation. Its expression will be given later.

\section{MOMENTUM}

Integral momentum can be defined as $\overrightarrow{M_{D}}=\rho V_{D} \vec{U}$. Its transport equation can be written as follows.

$$
\frac{\mathrm{d} M_{D}}{\mathrm{~d} t}+\oint_{\partial D} \rho \vec{U} h\left(\vec{U}-\overrightarrow{V_{w}}\right) \cdot \vec{n} \mathrm{~d} l
$$

$\{1\}$

$\{2\}$

$$
=\underbrace{-\oint_{\partial D} p_{h} h \vec{n} \mathrm{~d} l}_{\{3\}}+\underbrace{\vec{T}_{g}}_{\{4\}}-\vec{T}_{w}+\rho \underbrace{\rho V_{D} \vec{g}}_{\{5\}}+\underbrace{\vec{S}_{M}}_{\{6\}}
$$

In the left hand side, $\{1\}$ is the Lagrangian time derivative of the momentum $\vec{M}_{D}$ and $\{2\}$ is the convective momentum term. The first term in the right hand side $\{3\}$ comes from the pressure gradient. The total pressure $p_{h}$ includes three contributions:

$$
p_{h}=p_{d}+p_{g}+p_{c}
$$

- the pressure $p_{d}$ is due to the spray impact on the liquid film interface. If we note $n$ the number of droplets which have impinged $\left(\delta_{p}=1\right)$ and splashed $\left(\delta_{p}=-1\right)$ on the wall area $A_{w}$ during the time interval $\Delta t$, the impact pressure is given by:

$$
p_{d}=\frac{4 \pi}{3 \Delta t} \sum_{p}^{n} \delta_{p} \cdot r_{p}^{3}\left(\vec{V}_{p} \cdot \overrightarrow{n_{w}}\right)
$$

with $r_{p}$ the radius of the incident or the splashed droplets $p$ and $\vec{V}_{p}$ its relative velocity and $\vec{n}_{w}$ is the unit outward normal vector to the wall.

$-p_{g}$ is called the gas impact pressure in $\{20\}$. It represents the pressure which gradient may induces a strong deformation of the liquid-air interface. This phenomenon can be observed when a gas jet blows away a liquid free interface. This phenomenon cannot be taken into account in Kiva due to inadequate wall mesh refinement. Using the Bernouilli Equation, the static pressure gradient at the interface is approximated by the dynamic pression gradient obtained from the gas speed within the bulk gas adjoining the film. This impact pressure $p_{g}$ takes the following expression:

$$
p_{g}=\rho_{g}\left(\vec{U}_{g} \cdot \overrightarrow{n_{w}}\right)
$$

with $\rho_{g}$, the gas density. $\overrightarrow{U_{g}}$, the relative gas velocity to the wall.

$-p_{c}$ is the capillary pressure which arises from air-liquid interface curvature. A non dimensional study carried out in [22] has shown that $p_{c}$ is negligible for typical engine operating conditions. This is true exepting near the edge of the liquid film where the curvature radius becomes small. In this study, we assume that $p_{c}=0$.

The liquid-gas shear stress $\{4\}$ is given by:

$$
\overrightarrow{\mathrm{T}}_{g}=\left.A_{w} \mu_{g} \frac{\partial U_{g}}{\partial z}\right|_{z=h}=A_{w} \overrightarrow{\tau_{s}}
$$

where $\overrightarrow{\tau_{s}}$ is calculated by a modified law of the wall using the relative velocity $\overrightarrow{U_{g}}$ to the film and wall motion. This allows acceleration of gas by liquid film flow and conversely.

To compute the wall shear stress $\{5\}$, we assume a laminar parabolic liquid velocity profile following Mudawar [24] experiments. Using a zero liquid velocity at the wall and the continuity of the velocity and shears at the interface give the following expression for the wall shear stress.

$$
\overrightarrow{\mathrm{T}}_{w}=a_{\tau} \frac{\mu A_{w}}{h}\left(\vec{U}-\overrightarrow{V_{w}}\right)-b_{\tau} \overrightarrow{\mathrm{T}}_{g}
$$

where $a_{\tau}=3, b_{\tau}=1 / 2$.

In this relation, we assume that the liquid-air interface area is equal to the wall face area $A_{w}$. This may not be adequate in the spray impingement zone. This problem should be adressed in futur work.

The two last terms in (3) are the body force $\{6\}$ and a source force $\{7\}$ which will be given further. 


\section{ENTHALPY}

Since the internal energy and the enthalpy are similar quantities for incompressible liquid, the integral energy equation is written using the enthalpy defined as $H_{D}=c_{p} \rho V_{D} T$, in the following form:

$$
\begin{aligned}
& \frac{\mathrm{d} H_{D}}{\mathrm{~d} t}+\oint_{\partial D} \rho c_{p} T h\left(\vec{U}-\overrightarrow{V_{w}}\right) \cdot \vec{n} \mathrm{~d} l=J_{g}-J_{w}+S_{H} \\
& \underbrace{\sim \sim}_{\{2\}} \sim
\end{aligned}
$$

where $\{1\}$ is the lagrangian time derivative of the enthalpy, $\{2\}$ is the convective enthalpy term, $\{3\}$ is the gas heat flux, $\{4\}$ is the wall heat flux and $\{5\}$ is a source term which will be expressed in the next section:

- The gas heat flux $J_{g}$ is obtained using the interface condition:

$$
J_{g}=\left.A_{w} k \frac{\partial T}{\partial z}\right|_{z=h}=A_{w} \cdot\left(j_{g}-\dot{m}_{v} L\right)
$$

where $j_{g}$ is the liquid-air heat flux given by a modified heat transfer law of the wall taking into account the presence of the film on the wall. $\dot{m}_{v}$ is the rate of fuel vaporization described in the next section and $L$ is the latent heat of vaporization which depends on the liquid temperature.

- The wall heat flux $J_{w}$ was derived using wall temperature $T_{w}$. We assume a parabolic temperature profile to obtain the following expression:

$$
J_{w}=a_{J} k \frac{A_{w}}{h}\left(T-T_{w}\right)-b_{J} J_{g}
$$

where $a_{J}=3$ and $b_{J}=1 / 2$. The thermal conductivity $k$ is calculated using the Latini et al. method [25]:

$$
k=\alpha \frac{T_{b}^{1.2}\left(1-\frac{T^{0.38}}{T_{c}}\right)}{\sqrt{M_{f}} T^{1 / 6}}
$$

where $M_{f}$ is the molecular weights of the fuel and, $T_{b}$ and $T_{c}$ are its normal boiling and critical temperatures. The coefficient $\alpha$ is equal to $350 \mathrm{erg} / \mathrm{cm} \mathrm{Ks}$ [25].

\section{EXPRESSION FOR SOURCE TERMS}

\subsection{Volume Source Term $\dot{s}$}

We distinguish two origins for the volume source term in the integral mass conservation Equation (2):

$$
\dot{S}=\dot{S}_{d}+A_{w} \cdot \frac{\dot{m}}{\rho}
$$

$\dot{S}_{d}$ is due to the spray impact on the liquid film interface. Denoting $\delta_{p}=1$ for the impinging drops and $\delta_{p}=-1$ for the splashed droplets, mass conservation gives:

$$
\dot{S}_{d}=\frac{4 \pi}{3 \Delta t} \sum_{p}^{n} \delta_{p} \cdot r_{p}^{3}
$$

$\dot{m}_{v}$ is the mass flow rate due to the film evaporation or condensation at the liquid-gas interface and to the vaporization occurring at the wall surface where its temperature is higher than the boiling temperature. Following Leduc [26] and O'Rourke et al. [15], Foucart [22] has taken into account the motion induced by the evaporation inside the gas boundary layer (e.g. the Stefan flow) to obtain the following explicit analytical expressions for the evaporation rate at the film surface:

- when the dynamic effects are dominant (high air speed):

$$
\dot{m}_{v}=\frac{\tau_{s}}{\left\|\overrightarrow{U_{\infty}}-\vec{U}_{s}\right\|}\left[\left(B_{M}+1\right)^{1 / S c}-1\right]
$$

- when the thermal effects are dominant (high air or wall temperature):

$$
\dot{m}_{v}=\frac{j_{s}}{c_{p g}\left(T_{\infty}-T_{s}\right)}\left[\left(B_{M}+1\right)^{1 / L e}-1\right]
$$

The liquid-air shear stress magnitude $\tau_{s}$ is computed from Equation (7) and the gas heat flux $j_{s}$ is defnined by Equation (10). The subsript $\infty$ and $s$ designate the gas free stream and liquid-air interface conditions. In one hand, $T_{s}$ is approximated by the integral film temperature $T$. In the other hand, $\vec{U}_{s}$ is calculated using a laminar parabolic liquid velocity profile. We have obtained the following expression:

$$
\vec{U}_{s}=\frac{3 \vec{U}-\vec{V}_{w}}{2}+\frac{h}{4} \frac{\overrightarrow{\tau_{s}}}{\mu}
$$

The Spalding mass transfer number is calculated using the mass fraction of fuel at the film interface, $Y_{s}$, and the free stream fuel mass fraction, $Y_{\infty}$ :

$$
B_{M}=\frac{\left(Y_{s}-Y_{\infty}\right)}{\left(1-Y_{s}\right)}
$$

$Y_{s}$ is obtained by:

$$
Y_{s}=\left[1+\frac{M_{a m b}}{M_{f}}\left(\frac{p}{\min (p, p v)}-1\right)\right]^{-1}
$$

where $M_{f}$ and $M_{a m b}$ are the molecular weights of the fuel and the ambiant gas, $p$ is the ambiant pressure and $p_{v}$ is the vapor pressure of the fuel at the liquid interface temperature. Following Hubbard [27], $c_{p g}$, the gas specific heat, $S c$, the Schmidt number and $L e$, the Lewis number are calculated using the thermophysical properties evaluated at the reference temperature: $T_{r}=T_{s}+1 / 3\left(T_{\infty}-T_{\mathrm{s}}\right)$. 
When the film temperature reaches the saturation temperature of the fuel, boiling may occur. In this case, the rate of vaporization is obtained from the following energy balance at the liquid-air interface:

$$
\dot{m}_{s h}=\frac{c_{p} \rho V_{D}\left(T_{s h}-T_{b}\right)}{A_{w} \Delta t L\left(T_{b}\right)}
$$

The superheated liquid temperature $T_{s h}$ is the solution of the energy equation (Eq. (29)) where $J_{g}$ is given by Equation (10) using the rate of evaporation $\dot{m}_{v}$. When boiling occurs, the liquid film enthalpy is also reset to:

$$
H_{D}=\rho V_{D}^{\prime} c_{p} T_{b}
$$

where the new liquid volume in the domain $D$ is given by:

$$
V_{D}^{\prime}=V_{D}-\frac{\dot{m}_{s h}}{\rho} \Delta t
$$

\subsection{Momentum Source Term $S_{M}$}

This term includes the momentum supply of the impinging and splashed droplets only in the tangential direction $\underset{t_{w}}{\vec{g}}$ to the wall.

$$
\vec{S}_{M}=\frac{4 \pi \rho}{3 \Delta t} \sum_{p}^{n} \delta_{p} \cdot r_{p}^{3}\left(\vec{V}_{p} \cdot \overrightarrow{t_{w}}\right) \overrightarrow{t_{w}}
$$

where $\overrightarrow{V_{p}}$ is the speed of the impinging or splashed droplet $p$.

\subsection{Enthalpy Source Term $S_{H}$}

Enthalpy conservation between impinging and splashed droplets and the film during a time step $\Delta t$ gives:

$$
S_{H}=\frac{4 \pi \rho}{3 \Delta t} \sum_{p}^{n} \delta_{p} \cdot r_{p}^{3} c_{p} T_{d p}
$$

where $T_{d p}$ is the temperature of the impinging or splashed droplet $p$. Splashed droplets are assumed at the same temperature as the liquid film located on the impinged wall face. The droplet splashing criteria are given in the next section.

\section{SPRAY-W ALL AND SPRAY-FILM IMPINGEMENT MODEL}

In this section, we describe a model for the simulation of spray-wall interaction. Key issues involved in the model formulation are:

- determination of the impingement regimes and the regime transition criteria;
- derivation of relations describing the post-impingement droplets characteristics for the different regimes.

Only the first item is dealt with in the present work. Many parameters are needed to simulate the parent drops and the secondary droplets behaviors after the impingement.

The model is formulated on the basis of literature findings. Beside the classical stick, rebound and spread regimes (Fig. 3) widely described in available overviews (see [2830]), two splashing regimes are introduced to take into account the atomization induced by high impact droplet velocity on dry or wet surfaces (Figs. 3 and 4). Wall is assumed to be dry when its temperature is higher than the Leidenfrost temperature $T_{L}$ [31]. The secondary droplet characteristics are calculated using the experimentatal work of Mundo et al. [32] for rough dry walls, and of Yarin and Weiss [33] for wet walls. For both cases, the splashing transition criteria may be expressed using the Weber and Reynolds numbers:

$$
\begin{aligned}
& W e=\frac{\rho\left(\vec{V}_{p} \cdot \overrightarrow{n_{w}}\right)^{2} d_{0}}{\sigma} \\
& \operatorname{Re}=\frac{\rho\left(\overrightarrow{V_{p}} \cdot \overrightarrow{n_{w}}\right)^{2} d_{0}}{\mu}
\end{aligned}
$$

where $d_{0}$ is the initial drop diameter.

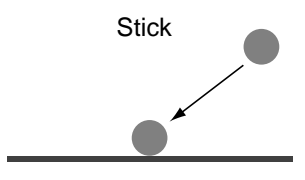

We $<5$

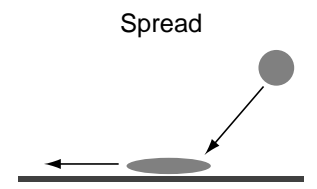

$80<W e<W e_{\mathrm{s}}$

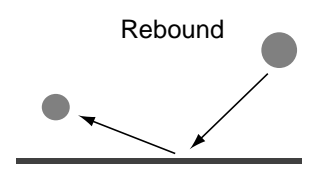

$5<W e<80$

Splash

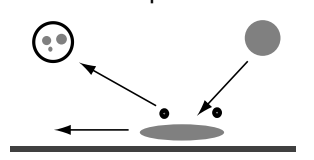

$W e<W e_{\mathrm{s}}$
Figure 3

Impingement on dry wall surface $\left(T_{w}>T_{L}\right)$ : regime transition criteria.

Following Yarin et al. [33] and Stanton et al. [19], when a liquid film is already on the surface the splashing threshold is given by:

$$
W e>W e_{s}=(18)^{2} d_{0}\left(\frac{\rho}{\sigma}\right)^{1 / 2}\left(\frac{\mu}{\rho}\right)^{1 / 4} f^{3 / 4}
$$


For a dry wall, following Mundo et al. [32], the splashing threshold is given by:

$$
W e>W e_{s}=\frac{(57.7)^{2}}{\sqrt{\operatorname{Re}}}
$$

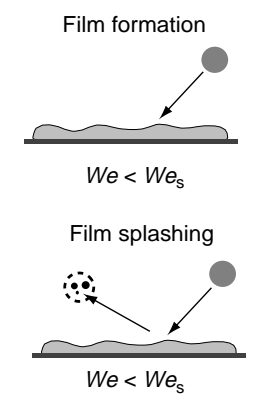

Figure 4

Impingement on wetted or partially wetted wall surface $\left(T_{w}<T_{L}\right)$ : Regime transition criteria.

\section{DISCRETIZATION}

We applied the Arbitrary Lagrangian Eulerian (ALE) scheme to solve the integral continuity, momentum and enthalpy film Equations (2), (3) and (9). A Lagrangian phase $L$ in which computational cells move with the liquid and an Eulerian phase $(n+1)$ in which the flow field is frozen and rezoned onto a new computational mesh. The equations are discretized in space using the finite volume method over typical quadrangular cells indexed by $I$ (Fig. 5) which are wall faces of Kiva-II cells.

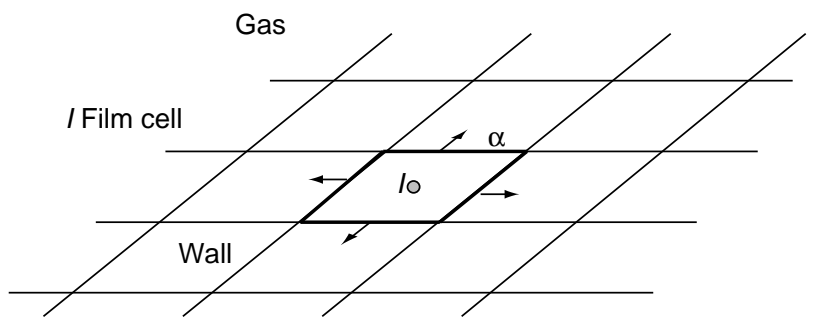

Figure 5

Bidimensional wall film cell $I$ and its edges $\alpha$.

\subsection{Lagrangian Phase $L$}

First order temporal differencing applied to the Lagrangian part of the integral equations gives the following implicit scheme for the Lagrangian phase:

- the volume of liquid film:

$$
V_{I}^{L}=V_{I}^{n}+\Delta t \cdot \dot{S}^{L}
$$

- the momentum of liquid film:

$$
\begin{array}{r}
\vec{M}_{I}^{L}=\frac{\left(h_{I}^{L}\right)^{2}}{\left(h_{I}^{L}\right)^{2}+a_{T} \mu \Delta t} \cdot\left[\vec{M}_{\mathrm{I}}^{n}+\Delta t\left(-\sum_{\alpha}\left(p_{h} h\right)_{\alpha}^{L} \vec{l}_{\alpha}^{L}+\rho V_{I}^{L} \vec{g}\right.\right. \\
\left.+a_{T} \mu A_{w} \frac{\vec{V}_{w}}{h_{I}^{L}}+\left(\left(1+b_{T}\right) \vec{T}_{g}^{L}+S_{m}^{L}\right)\right]
\end{array}
$$

- the enthalpy of liquid film:

$$
\begin{aligned}
H_{I}^{L}= & \frac{\left(h_{I}^{L}\right)^{2}}{\left(h_{I}^{L}\right)^{2}+} a_{j} \frac{k}{c_{p}} \Delta t \\
& \cdot\left[h_{I}^{n}+\Delta t\left(a_{j} \frac{k}{c_{p}} A_{w} \frac{T_{w}}{h_{I}^{L}}+\left(1+b_{J}\right) J_{g}^{L}+S_{H}^{L}\right)\right]
\end{aligned}
$$

\subsection{Eulerian Phase $(n+1)$}

The general explicitly discretized form for the Eulerian phase can be written as follows:

$$
(\mathbf{Q} V)_{I}^{n+1}=(\mathbf{Q} V)_{I}^{L}+\sum_{\alpha} \mathbf{Q}_{\alpha}^{L} h_{\alpha}^{L} \delta A_{\alpha}
$$

where:

$\mathbf{Q}=1$ for the continuity equation,

$\mathbf{Q}=\rho \vec{U}$ for the momentum equation,

$\mathbf{Q}=\rho c_{p} T$ for the enthalpy equation.

$\delta A_{\alpha}=\left(\vec{U}^{L}-\vec{V}_{w}\right)_{\alpha} \cdot \vec{l}_{\alpha}^{L} \Delta t$ is the area swept by each edge $\alpha$ of the wall film cell $I$ (Fig. 5) during the time step $\Delta t$. The possible mesh changes are taken into account by the velocity $\vec{V}_{w}$. It could be a wall motion (e.g. the tangantial component to wall) or a simple mesh relaxation. All film quantities are located at cell centers, so there is no need to compute liquid film velocity at the cell vertex. Therefore, edge unknowns $h_{\alpha}$ and $\mathbf{Q}_{\alpha}$ are evaluated by the upwind scheme of Kiva-II [7].

\section{EXPERIMENTAL VALIDATION}

\subsection{Film Formation and Transport in a Pipe}

To test liquid film formation, gas film interaction, film transport over complex geometries and accuracy of numerical methods, we use the spatial and temporal data base of liquid film thickness measured with a LIF technique described in Le Coz et al. [8]. It measures the thickness of a liquid film produced in a pipe by a pulsating spray.

The experiments were done in a transparent pipe, with constant air flow and pulsed injection; the measuring technique is based on laser-induced fluorescence, which has 
been adapted for local measurements through transparent pipe. The film is excited by laser light through the wall, and emits fluorescence whose amplitude is related to the excitation intensity, to the thickness of the film and to the fluorescence efficiency of the liquid fuel.

The set-up is described in Figure 6. Excitation is done by a $\mathrm{He}-\mathrm{Cd}$ laser whose wavelength is $441 \mathrm{~nm}$. The laser light is carried by an optical fiber and focused onto the inner surface of a transparent wall. A dichroic mirror splits the excitation wavelength from the fluorescence band emitted by the tracer. The test pipe is cylindrical having a diameter of $36 \mathrm{~mm}$, made of quartz and it is inclined $30^{\circ}$ with respect to the horizontal. A constant air flow is introduced in the pipe at atmospheric pressure. The pipe is fitted with a gasoline injector (Bosch EV 1.3A) to get pulsed injection with an angle of $45^{\circ}$. Here, iso-octane is injected with a supply pressure of 3 bars and 5\% of 3.4 hexanedione is added to act as a fluorescent tracer. The details of the operating conditions can be found in Table 1.

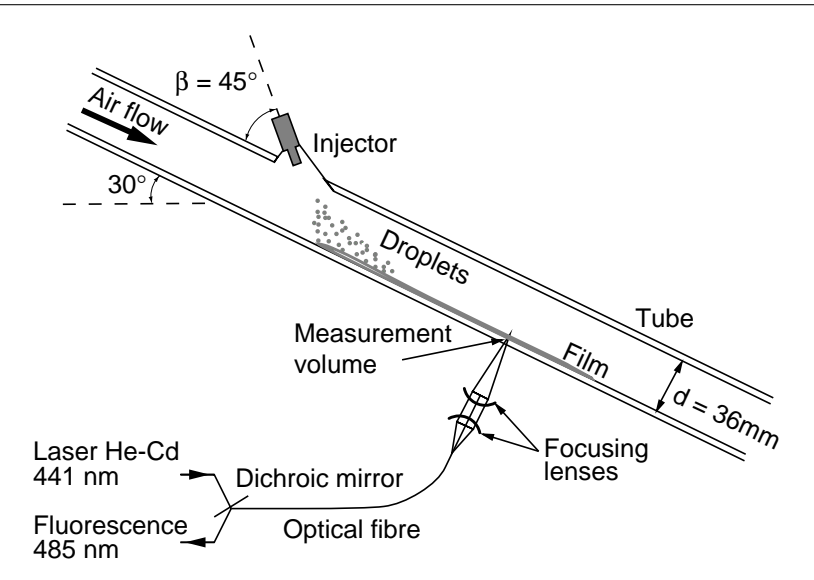

Figure 6

Set-up for film thickness measurement using laser-induced fluorescence.

When a stationary state has been reached, the tube surface is scanned in the region where a film is generated. The total mean film thickness spreading over a wide area on the botton of the pipe is averaged using about 100 injection shots.

In this study, we used the spray model of Kiva-II code with no droplet breakup or collision models activated. The parcels have been injected with a velocity equal to $16 \mathrm{~m} / \mathrm{s}$. We have specified a Sauter mean radius of $45 \mu \mathrm{m}$ for the injected droplets. Moreover, a solid spray was assumed with a cone angle of $30^{\circ}$ evaluated from the spray visualizations (see Table 1). To match the experimental spray visualizations, the injector angle is taken as $55^{\circ}$ instead of the actual $45^{\circ}$. This is necessary to reproduce the aerodynamic spray deviation and the weakly atomized spray obtained by such gasoline injector (Bosch EV 1.3A).
TABLE 1

Operating conditions

\begin{tabular}{l|c}
\hline Equivalence F/A ratio & 1 \\
Sauter Mean Diameter $(\mu \mathrm{m})$ & 90 \\
Droplet velocity $(\mathrm{m} / \mathrm{s})$ & 16 \\
Cone angle $\left(^{\circ}\right)$ & 30 \\
Inj. duration $(\mathrm{ms})$ & 6.7 \\
Angle injector/tube $\left({ }^{\circ}\right)$ & 45 \\
Injection frequency $(\mathrm{Hz})$ & 40 \\
Injected quantity per shot $\left(\mathrm{mm}^{3}\right)$ & 21.5 \\
Air flow rate $\left(\mathrm{m}^{3} / \mathrm{min}\right)$ & 0.42 \\
\hline
\end{tabular}

The mesh used in this study has cells with nearly $2 \mathrm{~mm}$ characteristic size.The number of injected parcels was 10000 . Furthermore, some modifications were made in Kiva-II to make multiple injection possible. The calculations are performed until reaching steady state liquid film flow as shown in Figure 7. Typical averaged spatial comparisons of the film thickness on the wall is shown in Figure 8. The numerical results are obtained by averaging the converged injection (e.g. all the numerical injection after the steady state is reached, say after $t=2 \mathrm{~s}$ ). Fairly good agreement is observed between the predictions (right side) and the LIF measurements (left side).

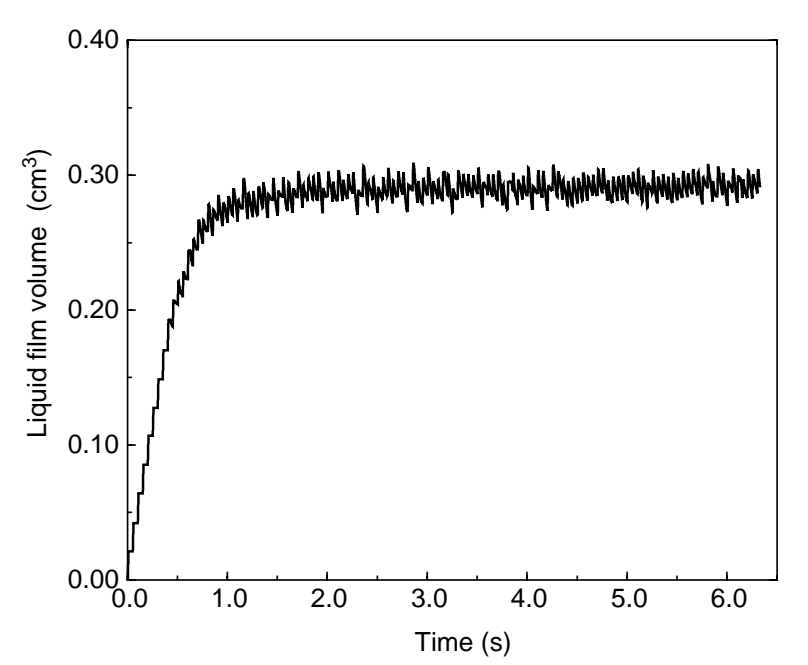

Figure 7

Total liquid film volume in the computational pipe.

\subsection{Spray Impingement on an Inclined Surface}

An experimental investigation was performed to visualize the shape of a transient gasoline spray impinging on an inclined surface. The experiments were carried out in a cell fitted with a pressure swirl injector (Siemens Deka DI 136) having a nozzle hole diameter of $0.55 \mathrm{~mm}$. Within the cell, a plate is fixed at $35 \mathrm{~mm}$ from the injector nozzle and inclined 


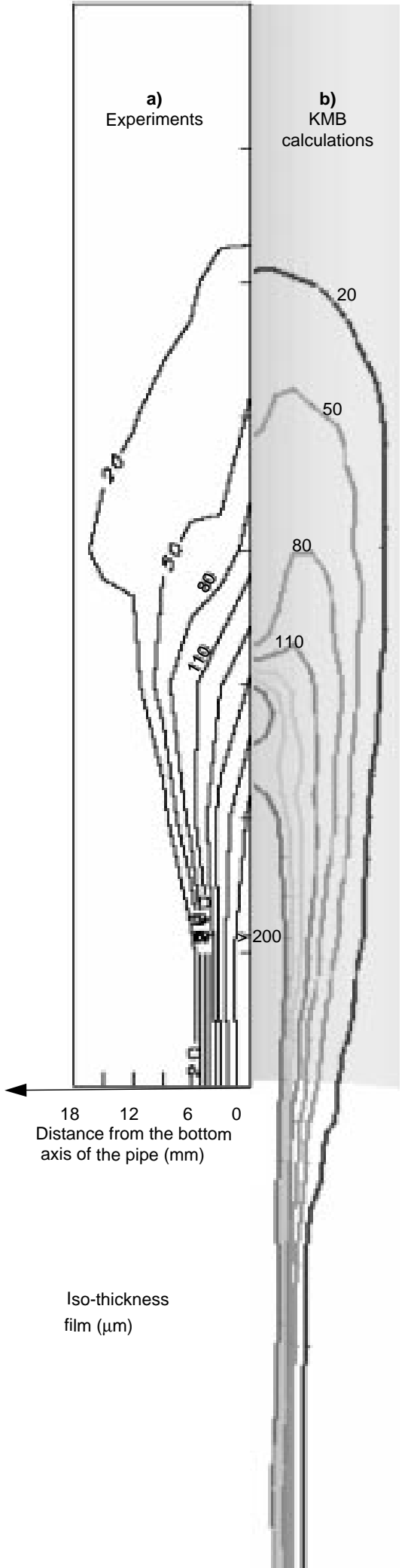

Figure 8

Comparison between predicted and measured spatial distribution of film thickness to $30^{\circ}$ with respect to the horizontal as shown in Figure 9 . The cell is filled with air at an ambiant temperature $\left(T_{a m b}=\right.$ $293 \mathrm{~K})$ and pressure $\left(P_{a m b}=0.12 \mathrm{MPa}\right)$. Here, iso-octane is injected with a supply pressure of 80 bar.

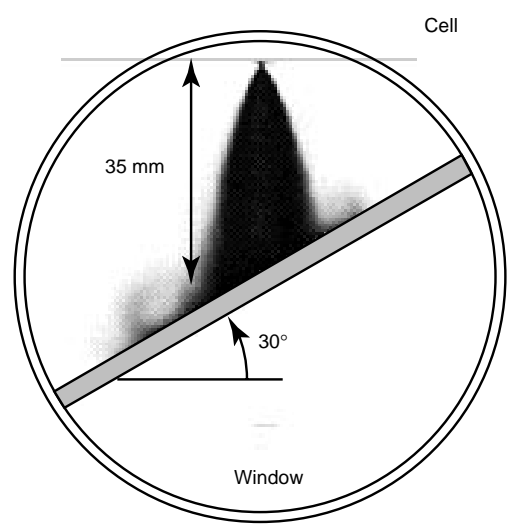

Figure 9

Cell arrangements for light extinction technique visualisation

The measuring technique is based on light extinction. The experimental results consist of averaged images of about 15 injections.

The details of the operating conditions can be found in Table 2.

TABLE 2

Operating conditions

\begin{tabular}{l|c}
\hline Injection frequency $(\mathrm{Hz})$ & 40 \\
Injection duration $(\mathrm{ms})$ & 1.5 \\
Injected quantity per shot $(\mathrm{mg})$ & 20.8 \\
Nominal cone angle $\left(^{\circ}\right)$ & 35 \\
\hline
\end{tabular}

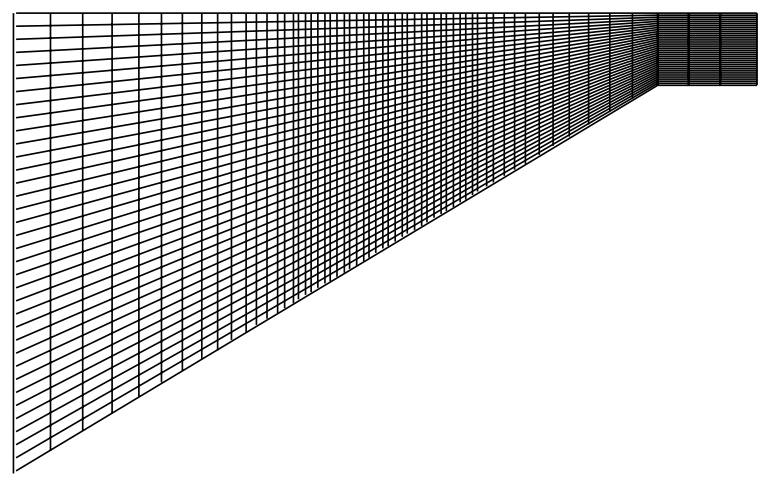

Figure 10

Computational mesh. A cut off trough the injector axis.

In this study, we used the spray model of Kiva-II the code with droplet breakup and collision models. The parcels have been injected with a velocity calculated using an 
experimental injection flow rate. To match the spray visualizations before the spray impingement, we have specified a Rosin-Rammler distribution with an exponent $q=3.5$ and a sauter mean radius of $15 \mu \mathrm{m}$ for the injected droplets. To simulate the pre-jet observed experimentally, the specified cone angle is linearly interpolated between 0 and $35^{\circ}$ during the first $0.5 \mathrm{~ms}$. Moreover, the needle rebound is taken into account by an extension of the injection duration from 1.5 to $2.0 \mathrm{~ms}$.

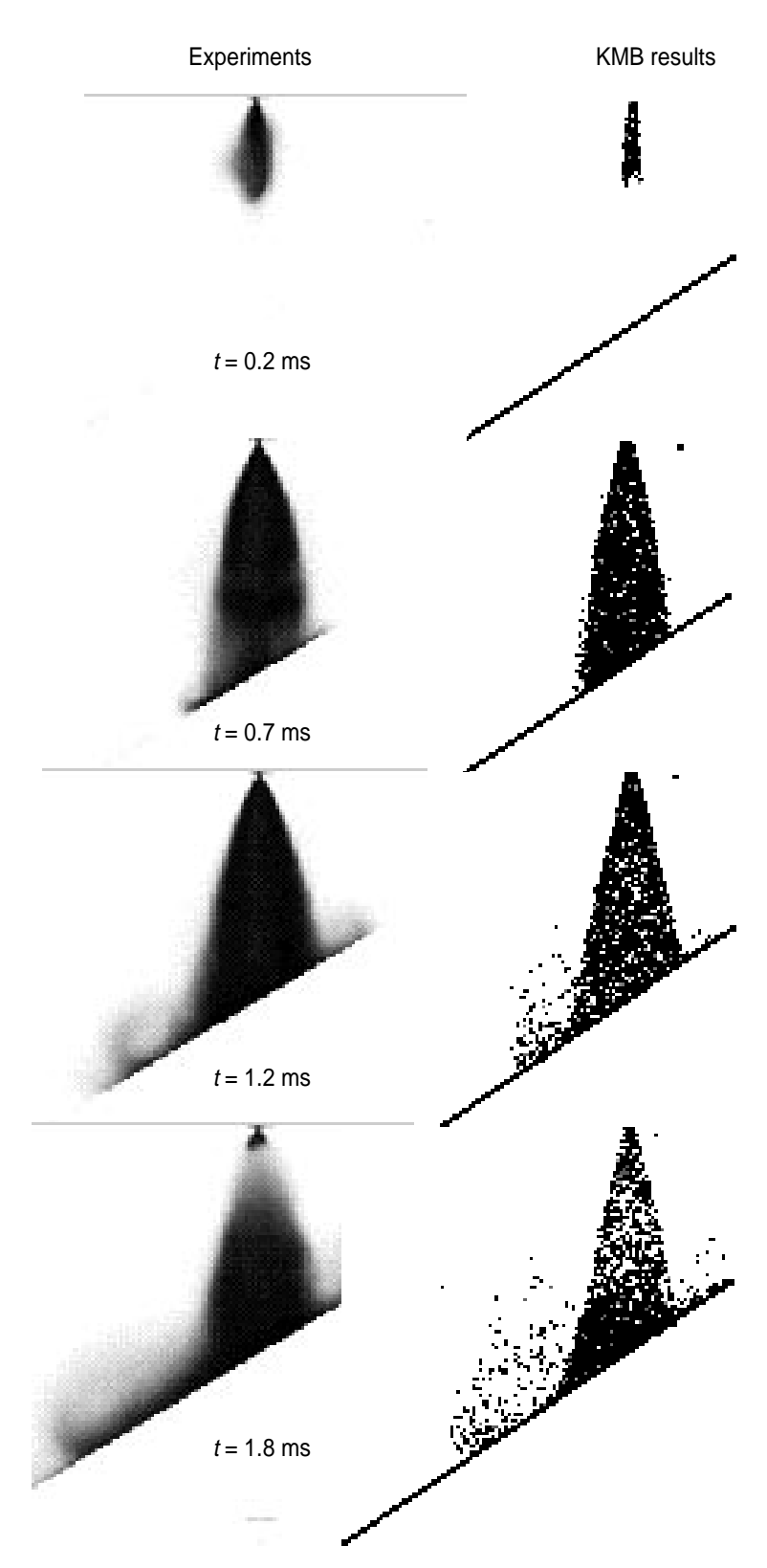

Figure 11

Comparison of calculated and measured spray shape during injection.
The mesh used in this study consists of cells with nearly a $1 \mathrm{~mm}$ characteristic size in the spray region as shown in Figure 10. The number of injected parcels was 15000 . Fairly good agreement is observed between the spray shape predictions on the right side and the measurements on the left side (see Fig. 11).

\section{ENG INE CALCULATIONS}

In this section, the wall-spray interaction and film models are tested for a realistic engine geometry. The models are applied to the injection and combustion processes in a wide spacing GDI engine under stratified charge operating conditions. Details about the combustion model used for the calculation of such stratified operations may be found in Duclos et al. [14].

In the wide spacing concept, fuel is transported to the spark plug by air entrainment and by impingement and sliding on the piston top. Therefore, piston temperature is one of the important parameters of mixture preparation. Five calculations have been done varying piston temperatures from 300 to $500 \mathrm{~K}$.

The computations begin at injection start, 60 CAD before top dead center. The details of the operating conditions can be found in Table 3. To overcome some difficulties related to spray modeling, we first fitted the spray shape to available experimental visualizations obtained by injection in the cell (without plate) described in the last section. This was obtained by specifying a 55 degrees hollow cone spray with an initial velocity equal to $42.5 \mathrm{~m} / \mathrm{s}$ and an initial droplet size sampled in the Rosin-Rammler distribution with a spread exponent $q=3.5$ and a sauter mean radius of $15 \mu \mathrm{m}$. As it is assumed that the flow field is generated by the spray momentum for stratified charge operation conditions, the ambiant gas was assumed to have an initial zero mean velocity.

TABLE 3

Operating conditions

\begin{tabular}{l|l}
\hline tr/min (rev/mn) & 2000 \\
Cone angle $\left(^{\circ}\right)$ & 55 \\
Injection duration (CAD) & 8.4 \\
Injection starting (CAD) & 59 BTDC \\
Injected quantity per shot (mg) & 4.5 \\
\hline
\end{tabular}

Figure 12 shows the liquid film mass on the piston versus wall temperatures. For cold operation or cold start, up to $25 \%$ of injected mass forms a liquid film on the piston bowl bottom. Increasing piston temperature decreases the gasoline film amount. No significant liquid film remains on the piston when its temperature exceeds the mean of the boiling and Leidenfrost temperatures $(460 \mathrm{~K}$ for the present operating 
conditions). This result agrees well with the available experimental obervations which confirm the absence of liquid film when piston temperature exceeds $460 \mathrm{~K}$.

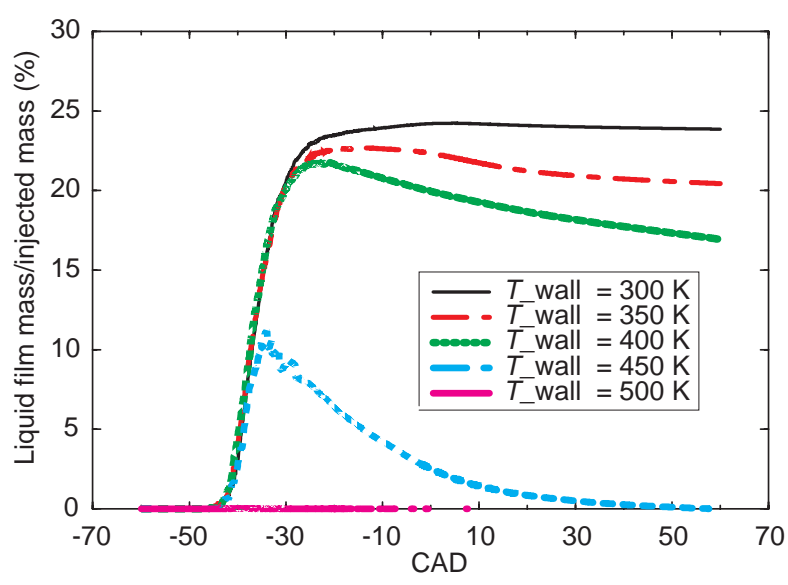

Figure 12

Liquid film mass on the piston versus wall temperatures.
For the cold operation case $\left(T_{\text {piston }}=300 \mathrm{~K}\right)$, the spray impacts the piston and forms a liquid film as shown in Figure 13. After top dead center (TDC), film evaporation is very slow despite the high ambiant gas temperature in the combustion chamber. A liquid film having $10 \mu \mathrm{m}$ thickness remains at the piston bowl surface at $60 \mathrm{CAD}$ after TDC. This situation must be avoided to ansure good mixture preparation and combustion. Moreover, liquid film may get the latent heat of vaporization from the pistonwall decreasing the air cooling effect and the compression ratio.

Figure 14 gives the gasoline rate during the compression and expanding strokes for two piston temperatures: 400 and $500 \mathrm{~K}$. In both cases, all the available gasoline vapor was burned. Due to the very slow film evaporation on the piston, a significant amount of unburned gasoline (about 20\% of the injected mass) is produced for the $400 \mathrm{~K}$ case (Fig. 14a). This result highlights a poor combustion shown also by the pressure curve evolutions (see Fig. 15). This study shows that the combustion is affected by the liquid film formation on relatively warm piston surfaces.
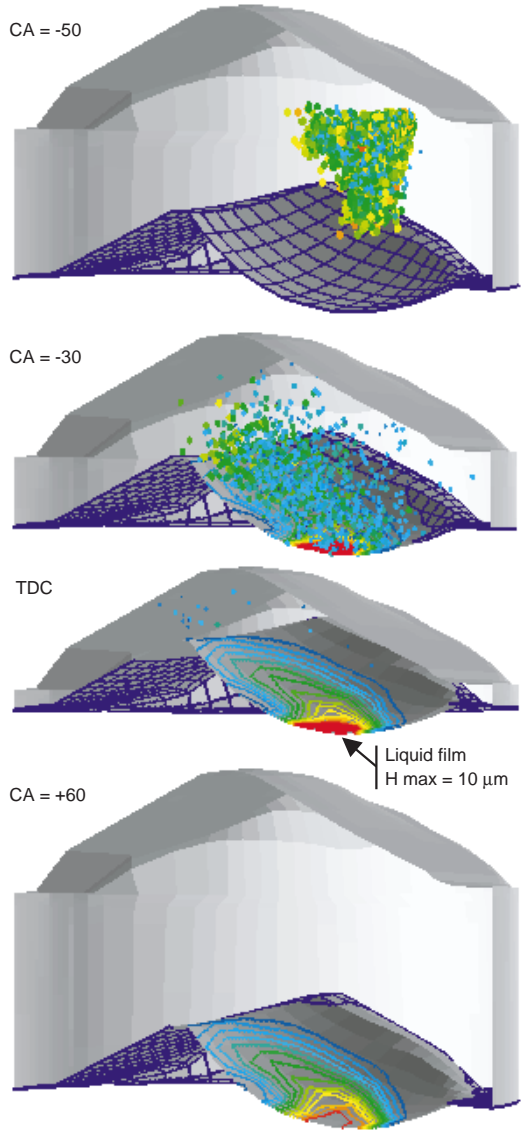

Figure 13

Liquid film formation and evaporation for the cold operation case $\left(T_{\text {piston }}=300 \mathrm{~K}\right)$.

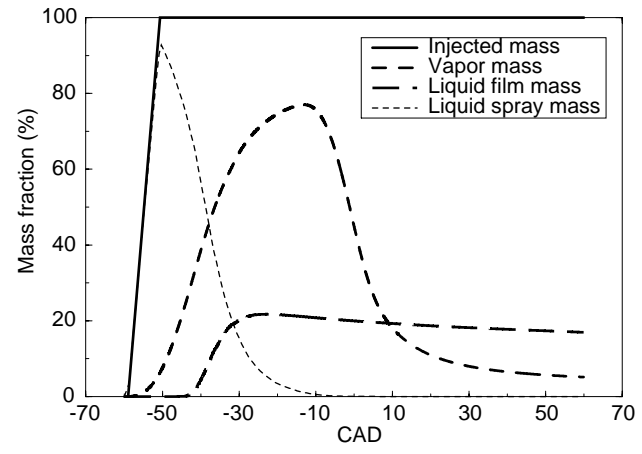

a) $T_{\text {piston }}=400 \mathrm{~K}$

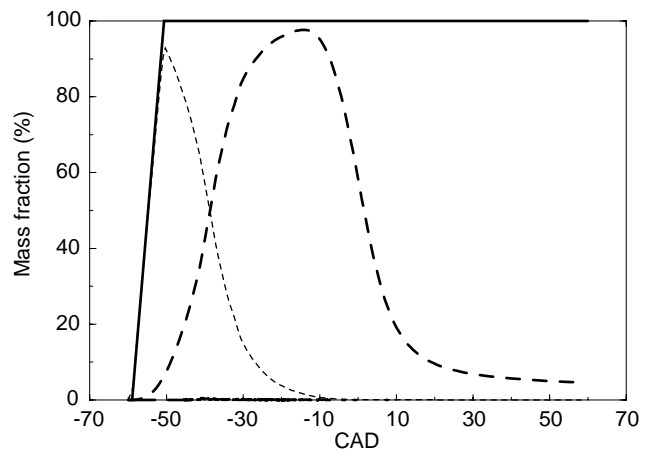

b) $T_{\text {piston }}=500 \mathrm{~K}$

Figure 14

Gasoline behavior 


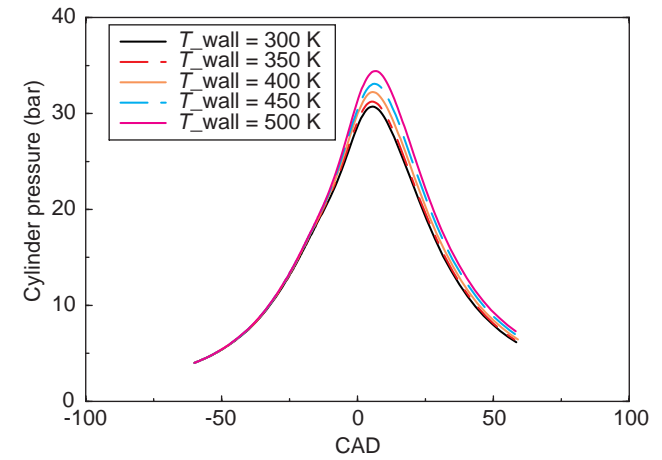

Figure 15

Pressure histories.

\section{CONCLUSIONS AND FUTURE WORK}

A wall-spray interaction and a film model have been developed and implemented in the KMB code. It gives relatively good agreement with LIF and light extinction experiments. Typical DI gasoline engine calculations demonstrate the potential usefulness of the wall-spray interaction and film models to predict mixture preparation.

This study shows that until the piston temperature reaches $400 \mathrm{~K}$, up to $20 \%$ of the injected gasoline remains liquid (e.g. unburned) on the piston bowl surface. No significant liquid film remains on the piston when its temperature exceeds the mean of the boiling and Leidenfrost temperatures.

More engine computations and comparison with data will allow in the future to assess and improve the spray and film models accuracy.

\section{ACKN O W LEDG MEN TS}

This research was funded in part by the GSM (Groupement Scientifique Moteur-PSA, Renault and IFP) and by the Commission of the European Communities and Eucar (Fiat, PSA, Renault, Rover, VolksWagen, Volvo) in the framework of the Joule II Idea Effect Programme and by the Commission of the European Communities in the framework of the Premix Joule III programme (Fiat, PSA, Imperial College and IFP). The authors are also indebted to J.-F. Le Coz and L. Hermant for providing the experimental data used in this work.

\section{REFEREN CES}

1 Jackson, N.S., Stokes, J. and Whitaker, P.K. (1997) A Gasoline Direct Injection (GDI) Powred Vehicle Concept with 3 1/100 km Fuel Economy and EC Stage 4 Emission capability. EAEC Congress, Italy, July 1997.

2 Shimotani, K. (1996) Characteristics of Gasoline in-cylinder Direct Injection. JSAE, 9631632, Review 17.
3 Croissant, K. and Kendlbacher, C. (1997) Requirements for the Engine Management System of Gasoline Direct Injection engines. Congress "Direkteinspritzung im Ottomotor", Essen, Germany, mars 1997.

4 Itoh, T. (1997) Combustion Characteristics of a Direct Injection SI Engine in Nissan. Congress "Direkteinspritzung im Ottomotor", Essen, Germany, mars 1997.

5 Fu-Quan, Z., Ming-Chia, L. and Harrington, D.L. (1997) A Review of Mixture Preparation and Combustion Control Strategies for Spark Ignited Direct Injection Gasoline engines. SAE, No. 970627.

6 Habchi, C. and Torres, A. (1992) A 3D Multi-Block Structured version of the Kiva-II code. First European CFD Conference Proceedings, edited by $\mathrm{Ch}$. Hirch (Elsevier), 1, 502-512.

7 Amsden, A., O'Rourke, P. and Butler, T. (1989) Kiva-II: A Computer Program for Chemically Reactive Flows with Sprays. LA-11560-MS, Los Alamos.

8 Le Coz, J.F., Catalano, C. and Baritaud, T. (1994) Application of Laser Induced Fluorescence for Measuring the Thickness of Liquid Films on Transparent Wall. 7th Int. Symp. on Application of Laser Techniques to Fluid Mechanics, Lisbon.

9 Habchi, C., Verhoeven, D., Huynh Huu, C., Lambert, L., Vanhemelryck, J.-L. and Baritaud, T. (1997) Modeling Atomization and Break-Up in High-Pressure Diesel Sprays. SAE, No. 970881.

10 Zolver, M., Griard, C. and Henriot, S. (1997) 3D Modeling Applied to the Development of a DI Diesel Engine: Effect of Piston Bowl Shape. SAE, No. 971599.

11 Boudier, P., Henriot, S., Poinsot, T. and Baritaud, T. (1992) A Model for Turbulent Flame Ignition and Propagation in Piston Engines. In 24th Symposium (International) on Combustion, The Combustion Institute.

12 Baritaud, T., Duclos, J. and Fusco, A. (1996) Modeling Turbulent Combustion and Pollutant Formation in Stratified Charge SI Engines. In 26th Symposium (International) on Combustion, 2627-2635, The Combustion Institute.

13 Duclos, J. and Zolver, M. (1998) 3D Modeling of Intake, Injection and Combustion in a DI-SI Engine under Homogeneous and Stratified Operating Conditions. In Comodia 98, 335-340.

14 Duclos, J.-M. (1998) 3D Modeling of Combustion for DI-SI Engines. Proceeding of the "Rencontres Scientifiques de l'IFP", 3-4 december 1998.

15 O'Rourke, P.J. and Amsden, A.A. (1996) A Particle Numerical Model for Wall Film Dynamics in Port-Injected Engines. SAE, No. 961961.

16 Amsden, A.A. (1997) Kiva-3V: A Block-Structured Kiva Program for engines with vertical or Canted Valves. LA13313-MS, Los Alamos.

17 Nagaoka, M., Ohsawa, K., Crary, B., Yamada, T., Sugiura, S. and Imatake, N. (1997) Numerical Analysis of Fuel Behavior in a Port-Injection Gasoline Engine. SAE, No. 970878.

18 Stanton, W. and Rutland, C.J. (1996) Modeling Fuel Film Formation and Wall Interaction in Diesel Engines. SAE, No. 960628.

19 Stanton, D.W., Lippert, A.M., Reitz, R.D. and Rutland, C.J. (1998) Influence of Spray-Wall Interaction and Fuel Films on Cold Starting in Direct Injection Diesel Engines. SAE, No. 982584

20 Bai, C. and Gosman, A.D. (1996) Mathematical Modeling of Wall Films Formed by Impinging Sprays. SAE, No. 960626.

21 Ahmadi-Befrui, B., Uchil, N., Gosman, A.D. and Issa, R.I. (1996) Modeling and Simulation of Thin Liquid Films Formed by Spray Wall Interaction. SAE, No. 960627. 
22 Foucart, H. (1998) Modélisation tridimensionnelle des films liquides pariétaux dans les moteurs à combustion interne. Thesis, University of Rouen, France, December 1998.

23 Foucart, H., Habchi, C., Le Coz, J.-F., Baritaud, T. (1998) Development of a Three-Dimensionnal Model of Fuel Liquid Film for Internal Combustion Engines. SAE, No. 980133.

24 Mudawar, I. and Houpt, R.A. (1993) Measurement of Mass and Momentum Transport in a Wavy-Laminar Falling Liquid Film. Int. J. Heat Mass Transfer, 36, 17, 4151-4162.

25 Reid, R.C., Prausnitz, J.M., Poling, B.E. (1987) The Properties of Gases and Liquids. 4th ed., McGraw-Hill Inc.

26 Leduc, C. (1995) Modélisation de la condensation en film sur les parois d'une enceinte de réacteur. Thesis, University of Grenoble I, France.

27 Hubbard, G.L., Denny, V.E. and Mills, A.F. (1975) Droplet Evaporation: Effects of Transient and Variable Properties. Int. J. Heat Mass Transfer, 18, 1003-1008.

28 Naber, J.D. and Reitz, R.D. (1988) Modeling Engine Spray/ Wall Impingement. SAE, No. 880107.
29 Senda, J., Kobayashi, M., Iwashita, S. and Fujimoto, H. (1994) Modeling Diesel Spray Impingement on a Flat Wall. SAE, No. 941894.

30 Bai, C. and Gosman, A.D. (1995) Development of Methodology for Spray Impingement Simulation. SAE, No. 950283 .

31 Baumeister, K.J. and Simon, F.F. (1973) Leidenfrost Temperature. Its Correlation for Metals, Cryogens, Hydrocarbons, and Water. Transaction of the ASME. J. of Heat Transfer, 166-173, May 1973.

32 Mundo, C., Sommerfeld, M. and Tropea, C. (1995) DropletWall Collisions: Experimental Studies of the Deformation and Breakup Process. Int. J. Multiphase Flow, 21, 2, 151-173.

33 Yarin, A.L. and Weiss, D.A. (1995) Impact of Drops on Solid Surfaces: Self-Similar Capillary Waves, and Splashing as a new Type of Kinematic Discontinuity. Journal of Fluid Mechanics, 283. 